\section{Informed patients, reformed clinicians}

A patient-centred National Health Service is on its way, to a consulting room near you. Users are increasingly offered more options and more control over their health care. The Expert Patient Programme (EPP), patient access to electronic health records, lay access to the clinical evidence base and good chronic disease management, including self management, are changing the role of patients and the form, content and outcome of a consultation. While the innovators in the medical profession may relish the changes, some clinicians will need support to share healthcare with the patient.

Most patients want shared decision making. ${ }^{1}$ Shared decision making also appears to lead to better outcomes, at least in the short term and this coincides with a moral imperative to support the autonomous patient. ${ }^{2}$

The EPP will empower patients to come into the consulting room with a pro-active attitude, seeing themselves as co-producers of their health, as shared problem solvers, as experts in their own conditions. The evidence is strong that such patients do better and use NHS services less. ${ }^{3}$

The practice of copying letters to patients and patients' routine access to their electronic health record will force clinicians to change the way they communicate with patients and other clinicians. A number of practices already offer patients access to and copies of their notes. Record access appears to improve trust in the clinician and helps patients feel more confident $t^{4,5}$ while others report the benefits of copying letters. ${ }^{6}$ The approach puts a premium on honesty and openness. Most clinicians, often after initial scepticism, have found the process easy and beneficial to both themselves and patients.

Experience from the USA and UK in chronic disease management shows significant benefit from supporting patients with greater use of the telephone, the web and group appointments in which the clinician works with a number of patients at the same time - encouraging learning both from the clinician and each other. Patients have a central role in their own health, and interventions address psychological needs and enable patients to deal with anxiety and depression themselves. Reductions in the use of medical outpatient departments of $37 \%$ and of accident and emergency of $34 \%$ have been achieved; in diabetic care, lower $\mathrm{HbA1c}$ levels are achieved with reduced primary care, hospital and outpatient use. ${ }^{7}$ Confidence and reduction in depression are most clearly linked with good outcomes. In order to make this a reality, the clinician will need to trust the patient to take decisions about their own care.
So, there are significant benefits to patients from a 'patient centred NHS'. But what does it mean for clinicians? Speaking in relation to management of long-term conditions, Sobel in a presentation in 2003 summarizes the challenge:

'Transform didactic, information-based approaches into interactive, self-efficacy/confidence enhancing communication that strengthens patients' skills in problemsolving, goal-setting and action planning, self-tailoring, using available resources, forming a partnership with the clinician.'

Underpinning this partnership is the need to trust and respect the patient.

Clinicians first need to ascertain a patient's communication and information preferences. Then, trusting the patient to handle uncertainty and process information, allow the individual's preferences and values to play a role in decisions about health and disease.

There is evidence that most clinicians do not do this very well at the moment. A large proportion of patients want more information than they currently receive, ${ }^{8}$ although a smaller proportion actually want to take decisions about their care. Clinicians predict patients' preferences poorly and offer less control to patients than they want. ${ }^{9}$ Clinicians find it difficult to respond to patients who come with a clear agenda supported by good information. ${ }^{10}$ Misunderstandings and lack of shared decision making can lead to undesired consequences in prescribing. ${ }^{11}$ When patients' decisions do not coincide with the clinician's recommendations 'informed dissent' may result.

These are complex issues. Offering users information on its own is rarely sufficient to enable a change in decision. Many patients need additional support - a health care professional or peer support (talking with other patients or watching video clips of patients or reading their stories) and decision support such as a decision aid. How clinicians regard the information or support may affect the way patients use them.

Ultimately, decisions are located in the interaction between clinicians and patients. Information can become the basis for a new type of relationship, in which shared information becomes part of the two-way trust that is essential to a productive doctor-patient relationship Consultations in primary care are increasingly becoming an exchange between experts. The patient who is expert in the story of their own health and life, combined with greater self efficacy skills, presents an opportunity-with the right support and training, this patient has the potential to self manage their condition, improving outcomes and reducing utilization of health services.

These kinds of changes are not likely to be painless. Clinicians may find them disturbing and undermining, resenting further interference in the way they practise 
medicine. Most will welcome change, seeing partnership with the patient as productive. However, even with good will and commitment, clinicians will need support to put these ideas into practice. Success may depend on increasing the time available within consultations, may require improved ways of communicating risk to patients, and the acquisition of new communication skills. It is important to avoid the situation in which a patient, feeling clear about what they want from a consultation, built on good information and support, comes face-to-face with a clinician who refuses to engage in a discussion and insists on his/her own course of action. This sort of impasse will fuel suspicion and resentment.

There is a need to develop further training to make this kind of approach a success. Experience suggests that clinicians change behaviour when they can express concerns, particularly with users, in a safe environment. This has also been seen with the Patients as Teachers programmes. ${ }^{12}$

New sources of patient information and a changing role for the patient demand new ways of negotiating the relationship between clinicians and patients. Clinicians deserve support in grasping this opportunity.

\section{Brian Fisher ${ }^{1}$}

Anna Dixon ${ }^{2}$

\section{Alasdair Honeyman ${ }^{3}$}

${ }^{1}$ Wells Park Practice, Lewisham London; ${ }^{2}$ Strategy Unit, Department of Health, London; ${ }^{3}$ Lambeth Walk Practice, Lambeth, London, UK

Correspondence to: Dr Brian Fisher

E-mail: brian.fisher403@ntlworld.com

\section{REFERENCES}

1 Coulter A, Magee H. The European Patient of the Future. Maidenhead: Open University Press, 2003

2 Coulter A, Elwyn G. What do patients want from high-quality general practice and how do we involve them in improvement? Br J Gen Pract 2002;52 suppl:S22-6

3 Lorig K, Holman H, Sobel D, et al. Living a Healthy Life with Chronic Conditions. Palo Alto: Bull, 2000

4 Baldry M, Cheal C, Fisher B, et al. Giving patients their own records in general practice: experience of patients and staff. BMJ 1986;292:596-8

5 Fisher B, Britten N. Patient access to records: expectations of hospital doctors and experiences of cancer patients. Br J Gen Pract 1993;43:52-6

6 Jelley D, van Zwanenberg T. Copying general practitioner referral letters to patients: a study of patients' views. Br J Gen Pract 2000; 50:657-8

7 Sadur CN, Moline N, Costa M, et al. Diabetes management in a health maintenance organization. Efficacy of care management using cluster visits. Diabetes Care 1999;22:2011-17

8 Bruera E, Willey JS, Palmer JL, Rosales M. Treatment decisions for breast carcinoma: patient preferences and physician perceptions. Cancer 2002;94:2076-80

9 Stevenson FA, Barry CA, Britten N, Barber N, Bradley CP. Doctorpatient communication about drugs: the evidence for shared decision making. Soc Sci Med 2000:50:829-40

10 Entwistle VA. Supporting and resourcing treatment decision-making: some policy considerations. Health Expect 2000;3:77-85

11 Montgomery AA, Fahey T. How do patients' treatment preferences compare with those of clinicians? Qual Health Care 2001;10 suppl 1: i39-43

12 Fisher B, Gilbert D. Patient involvement and clinical effectiveness. In: Gillam S, Brooks F, eds. New Beginnings: Towards Patient And Public Involvement In Primary Health Care. London: King's Fund Publication, 2001 